\title{
MICKEY, ZÉ COLMEIA E CIA: VERTENTES DO CINEMA DE ANIMAÇÃO (1920 - 2015)
}

\section{RESUMO}

Fernando Luiz

fer.luiggi@ hotmail.com

Universidade do Oeste Paulista,

Presidente Prudente, São Paulo, Brasil.
Índices expressivos de bilheteria atestam que o gênero animação é aclamado por crianças e adolescentes, embora não integre, de maneira efetiva, o cotidiano escolar, que prioriza a leitura do cânone literário a partir de uma proposta metodológica ainda didatizadora, monológica e estruturalista. Os desenhos animados, desse modo, penetrariam nas unidades de ensino como gênero marginal, vivo e incisivo nas falas e comportamentos dos alunos. Tendo em vista esse quadro, a presente pesquisa tem como principal objetivo problematizar as propostas estéticas veiculadas em desenhos tradicionais e contemporâneos, produzidos, divulgados e comercializados em diferentes países. Para tanto, a investigação, fundamentada no dialogismo bakhtiniano, analisou duzentas e quinze produções lançadas ao longo de quase cem anos, comercializadas em DVDs ou disponibilizadas na internet, especificamente no You Tube. Almeja-se, desse modo, a partir dos recursos empregados pelos estúdios na tecitura do texto visual e das múltiplas vozes instauradas ao longo dos desenhos, identificar as propostas artísticas tanto em narrativas mais "formais", veiculadas entre os anos de 1960 e 1970, quanto nas produções mais "arrojadas", firmadas após a década de 1990, de natureza polissêmica e emancipatória, marcadas pela metalinguagem, pela polifonia, pela incidência de heróis excêntricos, por anacronismos, pelas inúmeras alusões à cultura pop e, em especial, pela intertextualidade.

PALAVRAS-CHAVE: Desenho animado. Estética. Dialogismo. Infância. Ideologia. 


\section{INTRODUÇÃO}

A pesquisa Poéticas do Cinema de Animação tem como principal meta identificar, mapear e problematizar as propostas estéticas que orientaram os desenhos animados ao longo do século XX. Para tanto, foram abordadas duzentas e quinze produções, divulgadas entre 1920 e 2015. A rigor, justifica-se em meio à necessidade de uma reflexão um pouco mais aprofundada acerca dos desenhos veiculados no cenário contemporâneo em DVDs, TV e internet. Nota-se que tal gênero quase sempre é abordado como apêndice da história do cinema - o que elucida a incipiente bibliografia endereçada a tal questão. Na verdade, as animações destinadas ao público infanto-juvenil inscrevem-se como produtos de inegável impacto no mercado cinematográfico. Seduzem, encantam e emocionam mediante roteiros que, marcados pelo hibridismo, transitam da comédia ao drama, do suspense à aventura, do romance ao musical. Tendo em vista esse quadro, o estudo que envolve a mencionada temática ocupa-se em discutir o caráter artístico e ideológico de um conjunto de animações que circulam (e circularam) dentro e fora de unidades públicas e privadas de ensino, abordando as propostas estéticas diluídas na composição de roteiros, cenários, heróis e, sobretudo, personagens crianças.

A fim de melhor problematizar a singularidade do desenho animado como produto plurissignificativo, altamente artístico, como também sua considerável relevância para a criança, optou-se por estabelecer uma periodização acerca da presente temática. Para tanto, dividiu-se as duzentas e quinze produções consultadas em quatro momentos distintos identificados como: período de formação, consolidação e legitimação do gênero (1920 - 1960), período de desenvolvimento e expansão do mercado (1960 - 1980), período das narrativas híbridas, de tom grandiloquente e épico (1980 - 2000) e, finalmente, o período pós-moderno (2000 a 2015), marcado pela multiplicidade de vozes de grupos até então marginais, secundários e excêntricos.

\section{A ORGANIZAÇÃO DA PESQUISA}

A presente investigação científica, de caráter documental, fundamenta-se nas vertentes teóricas que abordam a escritura artística não apenas em sua imanência, mas também em sua dimensão pragmática, examinando-a, prioritariamente, em sua historicidade, em sua horizontalidade e em sua verticalidade. Nessa linha, recorremos aos estudos de Stam (2003), Glaber (2009), Fossatti (2009) e Denis (2010). Ademais, a pesquisa também se pautou nas contribuições de Ariès (1978) no que diz respeito, especificamente, ao conceito de infância aqui tratado, e às pesquisas de Aumont e Marie (2003) e Xavier (2008), em torno da linguagem do cinema.

Paralelamente, estruturou-se mediante a leitura e compilação de duzentas e quinze animações, divididas, com base na cronologia, em quatro grupos. A opção por um quadro tão denso possibilitou mapear, de maneira efetiva, os modos de representação de crianças, famílias e outros grupos sociais, bem como as aspirações evidenciadas no mercado, a seleção de signos com base em determinado projeto ideológico e, sobretudo, a projeção de obras com propostas 
alternativas ao que era desenvolvido nos eixos Estados Unidos/ Canadá/ Inglaterra.

Ismail Xavier ${ }^{1}$ pontua que o cinema, embora tenha dado seus primeiros passos no século XIX, consolidou-se, definitivamente, somente no século XX. Promovendo o que o autor denomina como espetacularização da vida transformando o cotidiano em imagem - tornou-se, em pouco tempo, expressivo veículo de comunicação de massa. Até a década de 1950, inclusive, caracterizavase como principal meio de entretenimento, dividindo tal posto com o posterior advento da TV. Considerando as particularidades do cinema, a presente pesquisa optou pela discussão de um ramo particular nesse complexo debate: o cinema de animação. Os filmes inscritos em tal modalidade limitavam-se, em princípio, ao público infantil, atendendo, apenas mais tarde, os nichos juvenis e adultos. De acordo com Denis (2010), a animação constitui uma técnica empregada não apenas em desenhos, mas também em filmes de ação, terror, comédia e ficção científica. É o que se observa, por exemplo, em títulos revestidos de expressivos efeitos especiais, como E.T. O Extraterrestre (1982), O Senhor dos Anéis (2001, 2002 e 2003) e Avatar (2009) - sucessos de bilheteria em que mutantes, duendes e alienígenas eram criados em computador, animados por uma série de profissionais e, mais tarde, acoplados às cenas.

Moreno (1978), por sua vez, define o cinema de animação como toda criação cinematográfica realizada imagem por imagem. No cinema animado, "a concepção de filme é criada numa dimensão de irrealidade e descontinuidade não perceptível aos olhos antes de sua projeção em tela" (p.08). Dada a impossibilidade de abordar o cinema de animação em sua amplitude - tendo em vista a heterogeneidade de filmes que comportaria - fixar-nos-emos exclusivamente em uma seção dentro desse sinuoso e envolvente território: o desenho animado. Para Moreno, caracterizar-se-ia este pela construção de bonecos ágeis e estudo sistemático de seus movimentos (caminhar, correr, chorar, saltar, dançar etc).

\section{RÉPLICA E INVENÇÃO: O PROCESSO DE FORMAÇÃO DO DESENHO ANIMADO}

Problematizar os aspectos estéticos de uma época exige do pesquisador certo rigor metodológico. As orientações da crítica especializada - Zilberman (1982), Stam (2003), Xavier (2008), Gabler (2009), Fossatti (2009) e Denis (2010), entre outros - tornam-se imprescindíveis no que tange ao aparato teórico. Contudo, o cuidado na forma de abordar as animações se faz fundamental, até para não incorrermos em certos reducionismos. Não pretendemos, com este artigo, esgotar as possibilidades de análise do cinema gráfico, mas apresentar indicadores e tendências que possam auxiliar eventuais leituras. As narrativas mencionadas nesse estudo, inscritas no período de formação, consolidação $e$ legitimação do gênero desenho animado (1920 - 1960), podem ser reunidas em três grupos, filiando-se, assim, à fábula moderna, à literatura para crianças e à comédia de costumes. 
No primeiro grupo, importa examinar o metamorfismo universal (FOSSATTI, 2009) latente nos episódios. Tudo aqui pode ser criado, recriado e transformado, independente das leis da física. A elasticidade das personagens possibilita com que estiquem e encolham, imprimindo graça às histórias. Tanto o coelho Oswald quanto o Gato Félix (e mais tarde Donald, Pluto, os esquilos Tico e Teco e o implacável Pernalonga) envolviam-se em múltiplas peripécias e jamais se feriam. É como se seus corpos fossem imunes a acidentes e invulneráveis à morte.

Atendo-se às narrativas desse período, Silva (2004) polemiza a problemática da morte dentro das animações. As personagens aqui são agredidas, amassadas e esmagadas e, na cena posterior, já estão de pé. É como se a morte tivesse sido desintegrada e se encontrasse extinta do cotidiano das personagens. Para a autora, muitas séries desse contexto trabalhavam com uma fórmula bem previsível, não dispondo de nenhum elemento surpresa. Basta observar, como acentua Silva, as histórias do Papa-léguas, marcada pelos constantes insucessos do Coiote.

Atrelado a isso, com o advento do som, os episódios passaram a incluir concertos, óperas e sinfonias, incorporando, muitas vezes, a estrutura de um videoclipe. O desempenho das personagens era rigorosamente acompanhado pelas notas das melodias, em suas diversas cadências, o que acabava dinamizando a ação e estampando uma aura de espetáculo a cada sintagma. Os conflitos aqui abordavam situações do cotidiano, ambientados em um universo inocente e radiante. Ainda que os protagonistas não estivessem na condição de crianças, eles explicitavam, com recorrência, um comportamento pueril, calcado em uma visão de infância que se baseava na pureza e na ingenuidade.

A inserção de anti-heróis redimensiona a poética das animações, rompe com a atmosfera festiva tão comum às narrativas conservadoras e introduz episódios salpicados de violência. É o caso, por exemplo, do coelho Pernalonga e do pássaro Pica-pau. A violência, porém, não é gratuita. Elucida-se como um elemento pertinente à cena, aplicado ora para gerar humor, ora para denunciar e satirizar aspectos da sociedade. Nessa última situação, convém ainda mencionar o caso do inescrupuloso leitão de A Revolução dos Bichos. Revoltando-se contra o antigo proprietário do rancho e instituindo-se como novo czar da população até então oprimida, o porco se tornava um dos principais articulistas na reforma da Granja Solar. A crueldade com que explorava os animais do rancho acabava ganhando notoriedade e, como no romance original de Orwell, dava margem para a reflexão crítica em torno do comunismo.

Dada a complexidade das narrativas desse porte, os fabulários não contavam com rótulos maniqueístas, mesmo porque as definições de bem e mal pareciam aqui não estar muito claras. Especialmente quando os protagonistas assumiam a faceta de anti-heróis e não necessariamente gozavam de um desfecho harmonioso. Isso não acontecia no processo de releitura dos contos de fadas, prática iniciada pela Disney na terceira década do século XX. Heróis e heroínas, em parte realçados por traços europeus, eram perseguidos por madrastas invejosas, piratas rancorosos e feiticeiras ávidas por desforra. O triunfo das personagens virtuosas e a ruína de seus antagonistas se acentuavam como uma fórmula que se repetia a cada narrativa.

Nesse debate, é lícito afirmar que o humor sustentado pelo fabulário foi, então, substituído por uma verve sentimental, sensível, nostálgica e, muitas 
vezes, ingênua. Fossatti (2009), diante de tal painel, acrescenta que a pureza quase que virginal de Branca de Neve acabava se contrastando com os outros ícones femininos da época, principalmente Betty Boop, definida por suas curvas acentuadas, sexualidade aflorada e vestido curto.

Não obstante, os desenhos pertencentes à linhagem dos contos de fadas também exploravam o melodrama, emplacando sequencias bastante extensas em que as personagens se prestavam a números musicais. Possivelmente tal aspecto se deva à influência do longa 0 Cantor de Jazz, lançado em 1927. Nader (2007), inclusive, assegura que Walt Disney mostrou-se entusiasmado com a obra, uma vez que se tratava do primeiro filme sonoro, cheio de passagens ilustradas por melodias. Além disso, o gênero musical pouco a pouco caia no gosto popular, implementando-se como uma tendência no cinema que pouco a pouco se firmava após a segunda guerra mundial.

As adaptações em questão optavam ainda por atenuar a violência que predominava na literatura infantil e juvenil tradicional, especialmente nas escrituras ligadas a Giambatiste Basile e Charles Perrault. Por isso, voltavam-se continuamente às versões dos irmãos Grimm, condensando as narrativas e eliminando qualquer passagem sangrenta. Além disso, nota-se que as escolhas da Disney eram sempre respaldadas no cânone ou nos romances de expressiva popularidade da época. Os roteiristas desviaram de tal regra apenas com a produção de Ferdinando, o Touro (1936), Dumbo (1941) e Bambi (1942), de Munro Leaf, Helen Aberson e Félix Salten, abrindo espaço para uma literatura não tão divulgada. No geral, os anseios da empresa eram de oferecer às crianças títulos até então circunscritos às prateleiras das bibliotecas, mas que agora poderiam ser contemplados nas salas de exibição.

A caricatura humana recebia tratamento especial com Mr.Magoo, Popeye, Brutus e Olívia Palito. As formas gráficas não se subordinavam ao requinte dos estúdios Disney, evidenciando uma predileção pelo traço estilizado e pela sátira ao universo adulto. A rigor, tem-se aqui o que designamos como comédia de costumes, gênero cuja célula mater se encontrava na dramaturgia e que se conceituava pela composição de um olhar cínico e contestador em torno das regras e condutas sociais. O Pateta, da Disney, malgrado se encontrasse na condição de animal, protagonizava uma série de episódios em que atuava como condutor de veículos, cidadão exemplar e pai de família. Especificamente nessa série se entremostrava a projeção de algumas crônicas sobre o cotidiano do homem estadunidense, interiorano e de classe média. $O$ aspecto universal contido nos episódios possibilitava com que um público diversificado, heterogêneo, e não apenas norte-americano, se reconhecesse em cada situação. O humor nessa tendência se configurava, então, não por intermédio das estripulias das personagens, como no fabulário, mas a partir de quadros que tematizavam o distinto cidadão dos anos de 1950, o vovô com problemas de visão e o conturbado triângulo amoroso formado por um marinheiro, uma donzela e um estereotipado vilão.

Em outro polo, Superman e sua réplica intertextual, o Super-Mouse, iniciaram, nos anos de 1940, os primeiros desenhos centrados em heróis modelares, representante de uma coletividade e tributários da mitologia grecoromana e das novelas de cavalaria. Na verdade, constituíam animações que embarcavam no êxito dos protagonistas oriundos dos quadrinhos. Essa tendência 
ganhará adeptos a partir da década de 1960, em que muitas outras personagens migrarão das revistas para as grandes telas.

No geral, o cinema gráfico desenvolvido no início do século XX teve como referência o trabalho de Walt Disney e de sua equipe. Os desenhos que se impuseram posteriormente, como Pernalonga e Pica-pau, redimensionaram as propostas estéticas daquele contexto, intercalando personagens não necessariamente resolutos e dotados de hábitos exemplares, mas como criações complexas, dinâmicas, contraditórias e bem próximas do comportamento humano. Nos três grupos (a fábula moderna, a literatura para crianças e a comédia de costumes), igualmente presente se faz a intertextualidade, sobretudo no que diz respeito à paródia. As narrativas dialogavam com títulos bastante conhecidos do grande público, como o acervo lendário das Mil e Uma Noites², a saga de Robin Hood ${ }^{3}$ ou a ópera O Barbeiro de Sevilha ${ }^{4}$.

Em linhas gerais, bastante expressiva foi a produção cinematográfica, inscrita no gênero animação, projetada nas salas de exibição entre 1920 e 1960. Nesse circuito, desenvolveram-se os episódios pioneiros de Popeye, Betty Boop e Gato Félix, seguidos pela revolução conceptual instaurada por Walt Disney. Revolução essa impressa nas atuações de Mickey e na veiculação de uma série de desenhos em torno de títulos consagrados pela crítica - o cânone - e textos praticamente desconhecidos do grande público. Com o apogeu da Disney, outros estúdios, ainda que em menor grau, passaram a divulgar narrativas em que a subversão do anti-herói acabava se impondo na tecitura do discurso, como sugeriam os desenhos rubricados por Walter Lantz (Pica-pau) e, mais tarde, pela Warner, com a trupe de Pernalonga.

Ao todo, verificou-se que as trinta e três animações consultadas na presente fase (1920 - 1960) englobavam núcleos não muito heterogêneos de personagens. Compilando esse material, especialmente no que diz respeito aos protagonistas, constatou-se que a maior parte era masculina. Ressaltavam-se, especificamente, vinte e seis homens, contrastando-se com sete mulheres, identificadas como Betty Boop, Alice, Luluzinha e as princesas Cinderela, Aurora e Branca de Neve. Como se vê, a Disney sinalizava uma estética, ainda que requintada, bastante tradicional, preconizando a fragilidade feminina e a força intempestiva do homem branco, cristão e intrépido, latente nos arquétipos dos príncipes, maridos, cavaleiros e pais.

A incidência de heróis modelares se fez igualmente expressiva. Ao todo, eram vinte e nove protagonistas solidários a essa linhagem - a maior parte divulgada pela Disney - perante apenas quatro anti-heróis, cuja aparição devia-se possivelmente ao anseio de delinear propostas alternativas ao cinema de animação, simultâneo ao império de Mickey Mouse. Em última análise, resta atentar quanto à explícita presença de adultos ( vinte e cinco no total), revelando um evidente descompasso face a oito crianças detectadas como protagonistas de

${ }^{2}$ Popeye e Mr. Magoo exploravam tal universo, respectivamente, em O Marinheiro Popeye encontra Ali Babá e os Quarenta Ladrões (1937) e Mr. Magoo e As Mil e Uma Noites (1959).

${ }^{3}$ Conferir Pernalonga Hood (1939).

${ }^{4}$ Conferir o episódio homônimo da série Pica-Pau. 
animação. Dessas oito, apenas uma, Peter $\operatorname{Pan}^{5}$, integrava uma narrativa em que as relações familiares se aproximavam do modelo libertário proposto por Zilberman (1982), em que a ficção eleva os pequenos heróis a uma posição de autonomia frente às instâncias superiores e dominadoras dos adultos. Já Luluzinha, apesar de assimilar, na década de 1940, um modelo alinhado ao viés eufórico ${ }^{6}$, constituía um caso à parte. A personagem citada, devido à insubmissão e à acidez contestadora, parecia resistir à retórica moralizante que regia o curtametragem.

Com o tempo, estampou-se, entre 1960 e 1980, um novo quadro que, em parte, destoaria do que se visualizou até então. A Walt Disney e a Warner mantiveram a liderança, ao passo que a TV se firmava como principal meio de entretenimento, e não mais as salas de cinema. Entretanto, não conseguiram conter o boom de curtas atrelados aos nomes de Willian Hanna e Joseph Barbera, conhecidos, até aquele contexto, pelas aventuras de Tom e Jerry (1940).

\section{OS SUCESSORES}

Configurou-se, de 1960 a 1980 (período de desenvolvimento e expansão do mercado), um corpus bastante eclético para consulta e posterior problematização. O corpus em questão abrangia um quadro de cinquenta e cinco animações que giravam em torno do substrato fabular, dos núcleos familiares, da ficção de suspense e da trajetória de heróis afinados aos arquétipos dos mitos gregos. A expansão do mercado evidenciou nichos em outros polos fora do eixo norte-americano, possibilitando a criação de estúdios em novas realidades, como a Itália, a França, o Japão e o Brasil.

No geral, havia no exposto período um apego maior para com os heróis tradicionais, avatares do mito do Superman. Tais heróis, em sua totalidade homens, brancos e heterossexuais, firmavam-se partidários de valores como justiça, honra e verdade. Como os heróis gregos, eram aclamados pela coletividade e embrenhavam-se em missões redentoras. Em contrapartida, enquanto o Super-Mouse, em 1940, parodiava a ascensão do homem de aço, os heróis excêntricos e anti-heróis da ocasião surgiam na pele de Pepe legal, MandaChuva, Capitão Caverna e, de modo ainda mais explícito, no Recruta Zero.

Nota-se, ainda, os modelos diferenciados de representação da criança, caracterizando-a ora como agente irrelevante nas relações familiares (Pedrita e Bambam), ora como adultos em escala reduzida (Astro Boy). Ainda que sem o mesmo destaque, situava-se paralelamente o discurso de crianças capazes de se

${ }^{5}$ Com o objetivo de discorrer sobre o perfil dos protagonistas, elegemos apenas um representante emblemático de cada animação. Seria inviável, e praticamente inexequível, se estivéssemos com um corpus maior. Por isso, vale salientar que, no longa-metragem mencionado, revelavam-se outras crianças emancipadas, como Wendy, João e Miguel. Contudo, estamos contabilizando apenas Peter Pan.

${ }^{6}$ O modelo eufórico (ZILBERMAN (1982), p.88) privilegia os valores da existência doméstica com base em uma visão adulta dos fatos. Visão essa em que a assimetria entre a criança e seus progenitores ou responsáveis se torna bastante acentuada. $\mathrm{O}$ adulto, via de regra, é representado como um sujeito exemplar e detentor do saber, diluindo, ao longo de toda a diegese, seus propósitos moralizantes. 
afirmar em meio aos próprios dramas. Aproximar-se-iam, assim, do modelo emancipatório de infância em suas relações familiares, conforme as reflexões de Zilberman (1982). Desfilavam, com irreverência, o menino Mogli, o cervo Rodolfo, a pequena Dorothy e, em maior ou menor grau, o desolado Charlie Brown e seus companheiros. Impõe-se, entre eles, a concepção de criança como personagem cuja atuação envolvia uma força geradora que desencadeava toda a ação, todo o enredo, toda a narrativa.

Ademais, o período de desenvolvimento e expansão do mercado foi caracterizado pela presença exaustiva dos estúdios Hanna-Barbera. Das cinquenta e duas animações consultadas, vinte e nove pertenciam a tal grupo, que acabou se consolidando e ocupando um território até então dominado e quase monopolizado pelo império Disney.

Ademais, o desenho animado, em sua historicidade, englobava tardiamente um olhar libertador sobre mulheres, negros, homossexuais e, sobretudo, crianças. A maior parte das produções, desenvolvidas entre 1930 e 1980, preconizava uma relação assimétrica do adulto perante meninos, préadolescente e adolescente, exaltando-lhes a suposta submissão. Entretanto, sabe-se que, nas últimas décadas do século $X X$, ganhava força uma nova tendência: a de representar heróis primordiais na condição de jovens altaneiros. A mediação do adulto como indivíduo experiente e soberano - vale lembrar o enigmático Mestre dos Magos, de Caverna do Dragão (1983), e o paternal Jagua, de Thundercats (1985) - passou a ser esporádica. No geral, as personagens deviam lidar com seus dilemas e superá-los sem a intervenção de anciões, os quais, ainda que oniscientes, em nenhum momento demonstravam obsessão superprotetora. É o início do que designamos como período das narrativas híbridas, de tom grandiloquente e épico (1980 - 2000).

A década de 1980, dialogando com a proposta de revitalizar heróis do universo da nona arte, caracterizar-se-ia por animações ainda mais realistas, fixando-se em séries de curta duração, tom aventuresco e apropriação híbrida de monstros do substrato medieval e alienígenas da ficção científica. Compreende o período de advento de desenhos como Thundarr, o Barbado1 (1980), Caverna do Dragão (1983), He-Man (1983), She-Ra (1985), Thudercats (1985), Galaxy Rangers (1986) e Os Caça-fantasmas2 (1986). Tais desenhos recuperavam a estrutura dos contos de fadas tradicionais, sublinhando a magia, o maniqueísmo, os valores medievais e a constância de melhoramentos e degradações inscritas no itinerário do herói primordial, nítido representante de uma coletividade.

Dos sessenta títulos compilados nessa nova fase (1980 - 2000), verifica-se que as mulheres, ainda que não ocupassem o posto de protagonistas - exceto She-ra, a princesa de Ethéria - desfilavam como amazonas, secretárias ou feiticeiras. Diferenciavam-se das clássicas princesas da Disney, inspiradas na literatura tradicional dos irmãos Grimm, que rogavam pela presença masculina para reverenciá-las e livrá-las de determinada ameaça. As novas mulheres, desse modo, não mais se sujeitavam à imposição do pai, do amante ou do amigo. Porém, torna-se ainda difícil afirmar, de modo categórico, que aqui se configure abertamente a emancipação feminina, mas talvez o primeiro passo para o posterior surgimento de personagens na linha de Fiona (Shrek (2000)). As próprias heroínas da Disney, a partir desse novo contexto, não serão mais representadas com base em valores como recato, pureza e subordinação. Exemplo disso é Ariel, a protagonista de A pequena sereia (1989), capaz de 
desafiar a tradição imposta pelo próprio pai, o rei Tritão, e lutar contra as forças do destino para se tornar humana e conquistar o enérgico Érik.

Se a participação feminina ganhava nítidos avanços, o espaço reservados aos negros e gays entremostrava-se ainda bastante modesto. Panthro, de Thundercats (1985), Doc, de Galaxy Rangers (1986) e Winston Zeddmore, de Os Caça-fantasmas (1986), estavam entre as poucas e raras personagens de etnia africana detectadas. Por outro lado, representações homossexuais ainda eram tabus e alvos de estereótipos. Vaidoso, de Os Smurfs (1980), tinha comportamento efeminado e desejos fúteis, ao passo que o antagonista Ele, de As Meninas Superpoderosas (1998), exibia-se invejoso, hostil e também portador de exagerados trejeitos afeminados. Sua própria imagem dialogava com as figuras satânicas do universo bíblico.

No que tange à infância, é fora do contexto das narrativas híbridas que as crianças recebiam tratamento especial. $O$ jovem Fred Flintstone, o pequeno Scooby Doo, o engenhoso Perninha, a intrépida Mônica, o criativo Bobby Generic e o rol de filhotes de dinossauros de Em busca do vale encantado (1988) deixavam transparecer o discurso de hipervalorização do mundo infantil, concentrando o enredo em uma linha alternativa à tendência maniqueísta até então em vigor. Não havia, aqui, o embate entre forças antagônicas - benignas e malignas - mas o anseio em encontrar mecanismos para solucionar seus impasses. Em um novo contexto - marcado pelas contribuições teóricas de Jean Piaget, Sigmund Freud, Lev Vygotsky e Henri Wallon - pais e professores, responsáveis pela educação e socialização do sujeito, não eram apresentados como ícones coercitivos, exemplares e autoritários, mas como figuras que poderiam oferecer liberdade para que filhos e alunos refletissem sobre as próprias agruras.

No final da década de 1990, a tendência pós-moderna configurou-se mediante traços bastante singulares, como a ênfase à metalinguagem, a recorrência deliberada da intertextualidade, a mistura consciente de estilos e a incidência da alegoria. Assinala-se, em meio à filmografia veiculada no novo milênio, a presença exaustiva da categoria longa-metragem. Durante muito tempo, apenas a Disney investia em narrativas mais extensas, liderando o mercado cinematográfico com a releitura dos contos de fadas. Com o êxito de Shrek (2000), parte expressiva dos estúdios norte-americanos percebeu a possibilidade de se inserir no citado mercado, desafiando o império do camundongo Mickey. O resultado (identificado entre 2000 - 2015) foi o novo boom do cinema de animação, contabilizando elevadas cifras, roteiros demorados e criações erigidas ante a técnica da computação gráfica. Desfilavam, assim, figuras que, gradativamente, tornaram-se familiares aos pequenos leitores, como o leão Alex, o camaleão Rango, o urso Pô, o tubarão (vegetariano) Lenny e a hilário Megamente. Em maior ou menor grau, eram obras marcadas por tópicos que os estudos bakhtinianos classificariam como polifonia, carnavalização e dialogismo, abrangendo, também, múltiplas referências à cultura pop e, simultaneamente, à arte erudita.

Desse modo, observou-se nas sessenta e seteo narrativas consultadas que as verdades eurocêntricas e as certezas extremistas heterocêntricas acabavam sendo questionadas, desestabilizadas e problematizadas, edificando um discurso de tolerância e inclusão sem aderir a nenhum ranço utilitarista ou pedagógico. Firmando-se como uma expressão audiovisual, abusa de situações cômicas 
(gags), cria momentos em que contracenam atores e toons (cross over) e abre margem para pequenos videoclipes, ressaltando, assim, momentos mágicos em que partes do enredo são assinalados, tendo como fundo determinada melodia de forte apelo popular e comercial. Vigora, paralelamente, um conjunto de vozes variadas, oriundas das mais diversas camadas sociais, alinhadas ao multiculturalismo e marcadas pelo uso diversificado da linguagem. Encontravamse tais vozes diluídas na participação de uma miríade de personagens (o plebeu (A nova onda do imperador (2000)), os habitantes do submundo (Por água abaixo (2006)), os peixes adeptos à cultura negra norte-americana (O Espanta-Tubarões (2004)), o camaleão pícaro (Rango (2011)), os guetos cariocas (Rio (2011)) e o universo do Brasil interiorano (O Sítio do Picapau Amarelo (2012)). Por outro lado, merecem também destaque os modos como o passado histórico sobretudo a Idade Média e o Velho Oeste - são tratados face à ironia e ao humor desregrado. Assim, a historiografia oficial acabava sendo revisitada com sarcasmo, dessacralizando o mito do mártir emblemático, do herói clássico ou do cavaleiro astucioso. Evoca-se também o hibridismo explícito na maior parte das obras consultadas, que não se enquadravam em um único gênero, mas se abriam para ecléticas classificações, abarcando, simultaneamente, a comédia, o drama, a aventura e o suspense.

\section{CONCLUSÃO}

A trajetória da investigação científica permitiu a visualização de um complexo labirinto discursivo em que ganhava força, a partir dos princípios da dialogia, a interação entre o desenho animado e outros sistemas semióticos, como a literatura, os quadrinhos, a música, o folclore, a mitologia e o cinema "convencional". Nesse profícuo lastro cultural, evidenciava-se uma infinidade de propostas estéticas, transitando da geometrização das formas, com o astuto Gato Félix, ao figurativismo suntuoso e imponente da Disney; das formas ágeis e alongadas da Warner ao traço simples, limpo, intercalando poucos movimentos, da dupla Hanna-Barbera; da pop art e do psicodelismo de $\mathbf{O}$ submarino amarelo (1968) ao tom soturno de Tim Burton; da adaptação dos contos de fadas à releitura livre e envolvente de O Pequeno Príncipe (2015); do patriotismo exacerbado de Superman (1940) à contracultura de Asterix, o gaulês (1967) e Kiriku (1998); da construção caricata e simetricamente majestosa da computação gráfica ao delineamento de figuras com cores vivas e representação visual pouco realista, como sugerem Os Simpsons (1990) e Bob Esponja (2000) respectivamente. Constituíam um complexo corpus com mais de duzentas obras que, valendo-se da intertextualidade, operavam com a paródia, a alusão, o reboot e o crossover. 


\title{
MICKEY, ZÉ COLMEIA AND COMPANY: STRANDS OF ANIMATED CINEMA (1920 - 2015)
}

\begin{abstract}
Significant box offices show that the animation genre is acclaimed by children and adolescents, although it does not make part of the school routine effectively, which prioritizes reading the literary canon from a methodological proposal that is still monological and structuralist. The cartoons, in this way, would penetrate the units of education as a marginal, alive and incisive genre in the speeches and behaviors of the students. Considering that, the main objective of this research is to problematize the aesthetic proposals conveyed in traditional and contemporary designs, produced, divulged and marketed in different countries. Therefore, the research, based on Bakhtin's dialogism, analyzed two hundred fifteen productions launched during nearly a hundred years, sold on DVDs or made available on the internet, especially on YouTube. From the resources used by the studios in the construction of the visual text and the multiple voices established throughout the drawings, it is hoped to identify the artistic proposals in both more "formal" narratives, published between the years of 1960 and 1970, as well as in the more "daring" productions, marked after the 1990s, of a polysemous and emancipatory nature, marked by metalanguage, polyphony, the incidence of eccentric heroes, anachronisms, innumerable allusions to pop culture, and especially intertextuality.
\end{abstract}

KEYWORDS: Cartoon. Aesthetics. Dialogism. Childhood. Ideology. 


\section{REFERÊNCIAS}

ARIÈS, P. História Social da Criança e da Família. Rio de Janeiro: FCT, 1981.

AUMONT, J. \& MARIE, M. Dicionário Teórico e Crítico de Cinema. Campinas: Papirus, 2003.

DENIS, S. 0 Cinema de Animação. Lisboa: Edições Texto e Gráfica, 2010.

FOSSATTI, C. Cinema de Animação: uma trajetória marcada por inovações. Encontro Nacional de História da Mídia: mídias alternativas e alternativas midiáticas. Fortaleza, 2009.

GABLER, N. Walt Disney: o triunfo da imaginação americana. Osasco: Novo Século, 2009.

MORENO, A. A Experiência Brasileira no Cinema de Animação. São Paulo: Arte Nova, 1978.

NADER, G. A Magia do Império Disney. São Paulo: Editora Senac, 2007.

STAM, R. Introdução à Teoria do Cinema. Campinas: Papirus, 2003.

XAVIER, I. O Discurso cinematográfico: a transparência e a opacidade. São Paulo: Paz e Terra, 2008.

ZILBERMAN, R. A Literatura Infantil na Escola. São Paulo: Global Editora, 1982. 
Recebido: 29 dez.. 2016

Aprovado: 02 jun. 2017

DOI: $10.3895 /$ rl.v19n24.5260

Como citar: LUIZ, Fernando. Mickey, Zé Colméia e Cia: vertentes do cinema de animação (1920 - 2015)

R. Letras, Curitiba, v. 19, n. 24, p. 84-96, mar. 2017. Disponível em: <https://periodicos.utfpr.edu.br/rl>.

Acesso em: XXX.

Direito autoral: Este artigo está licenciado sob os termos da Licença Creative Commons-Atribuição 4.0

Internacional.

(c) (i) 